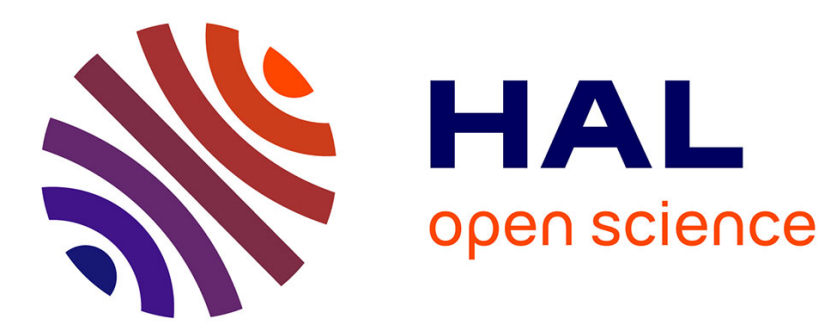

\title{
Tailoring the microstructure of an oriented graphite flake/Al composite produced by powder metallurgy for achieving high thermal conductivity
}

Zhengyan Shen, G Ji, Ahmed Addad, Christine Labrugère, Yongfeng Lu, Jean-François Silvain

\section{To cite this version:}

Zhengyan Shen, G Ji, Ahmed Addad, Christine Labrugère, Yongfeng Lu, et al.. Tailoring the microstructure of an oriented graphite flake/Al composite produced by powder metallurgy for achieving high thermal conductivity. Diamond and Related Materials, 2021, 118, pp.108513. 10.1016/j.diamond.2021.108513 . hal-03276773

\section{HAL Id: hal-03276773 \\ https://hal.science/hal-03276773}

Submitted on 2 Jul 2021

HAL is a multi-disciplinary open access archive for the deposit and dissemination of scientific research documents, whether they are published or not. The documents may come from teaching and research institutions in France or abroad, or from public or private research centers.
L'archive ouverte pluridisciplinaire HAL, est destinée au dépôt et à la diffusion de documents scientifiques de niveau recherche, publiés ou non, émanant des établissements d'enseignement et de recherche français ou étrangers, des laboratoires publics ou privés. 


\title{
Tailoring the microstructure of an oriented graphite flake/Al composite produced by powder metallurgy for achieving high
}

\author{
thermal conductivity \\ Zhengyan SHEN ${ }^{1,2,3}$, Gang $\mathrm{JI}^{2, *}$, Ahmed ADDAD ${ }^{2}$, Christine LABRUGERE ${ }^{4}$, Yongfeng $\mathrm{LU}^{5}$, \\ Jean-François SILVAIN ${ }^{1,5}$ \\ ${ }^{1)}$ CNRS, Univ. Bordeaux, Bordeaux INP, ICMCB, UMR 5026, F-33608 Pessac, France \\ ${ }^{2)}$ Univ. Lille, CNRS, INRA, ENSCL, UMR 8207 - UMET - Unité Matériaux et \\ Transformations, F-59000 Lille, France \\ ${ }^{3)}$ Institute of New Materials, Guangdong Academy of Sciences, Guangdong Provincial Key \\ Laboratory of Metal Toughening Technology and Application, Guangzhou 510650, China \\ ${ }^{4)}$ CNRS, Univ. Bordeaux, PLACAMAT, UMS 3626, F-33608 Pessac, France \\ ${ }^{5}$ Department of Electrical and Computer Engineering, University of Nebraska-Lincoln, \\ Lincoln, NE, 68588 \\ * Corresponding author: Dr. Gang JI (gang.ji@ univ-lille.fr)
}

\begin{abstract}
An Al matrix composite reinforced with 40 vol.\% graphite flake $\left(G_{f}\right)$ was developed by powder metallurgy as a promising candidate for thermal management applications. Thermal conductivity (TC) along the orientation direction of the composite sintered at $640{ }^{\circ} \mathrm{C}$ was measured to be $452 \mathrm{~W} / \mathrm{m} \mathrm{K}$, which is approximate to the highest TC value theoretically predicted by effective medium approximation model. The three underlying mechanisms responsible for such TC enhancement were clarified in terms of microstructure characterization. First, heat treatment of as-received $\mathrm{G}_{\mathrm{f}}$ under $\mathrm{Ar}+$ $\mathrm{H}_{2}$ atmosphere resulted in reduction of defects on the edge contributing to improvement of interface thermal exchange efficiency between $\mathrm{Al}$ and $\mathrm{G}_{\mathrm{f}}$. Second, image analysis quantitatively confirmed that a step-by-step die filling process using the spherical powder ensures the perfect orientation of $G_{f}$ in the Al matrix. Third, it was found that the TC of the composite increases with the sintering temperature from 580 to $640{ }^{\circ} \mathrm{C}$. The formation of a small amount of fine platelet-like $\mathrm{Al}_{4} \mathrm{C}_{3}$ at the interface between the side surface of $\mathrm{G}_{\mathrm{f}}$ and $\mathrm{Al}$ matrix indicates the desirable bonding state for minimizing interfacial thermal resistance, beneficial for the overall TC enhancement. Besides, the relevant coefficient of thermal expansion and bending
\end{abstract}


strength were discussed.

KEY WORDS: Graphite flake/Al composite materials; Thermal conductivity; Powder filling process; Sintering.

\section{Introduction}

In the modern electronic industries, heat dissipation has become a critical issue raised by rapid increase of high-power density and miniaturization of electronic components. This has become a major driving force for the development of electronic packaging materials with a high thermal conductivity (TC) improving the efficiency of heat removal, and tailored coefficient of thermal expansion (CTE) matching that of electronic chips $[1,2]$. Compared with pure metals, such as silver $(\mathrm{Ag})$, copper $(\mathrm{Cu})$, and aluminum (Al), all having the high TCs but undesirable CTEs, engineering a particulate-reinforced metal matrix composite (MMC) has been proved to be an effective solution to meet the requirement of both TC and CTE for thermal management applications [3, 4].

Nowadays, carbon-based reinforcement materials, such as graphite flake $\left(G_{f}\right)$ [5-7], diamond (D) [8], and short carbon fiber (CF) [9, 10], have become more and more attractive in MMCs because of their excellent thermal properties. It has been reported that the high TC has been achieved in D/metal composites (e.g., $475 \mathrm{~W} / \mathrm{m} \mathrm{K}$ for the 40 vol.\% D/Al composite [8]), while their drawbacks are relatively high cost and poor machinability $[8,11]$. Regarding CFs, how to orient them to obtain the high overall TC of composite is still a technical obstacle, since CFs always tend to be randomly distributed in the plane perpendicular to the pressing direction $[9,10]$. Among the above-mentioned reinforcements, $\mathrm{G}_{\mathrm{f}}$ is low cost, light weight, and easily machinable, which makes it a promising reinforcement candidate in MMCs used for electronics $[5,6,12-14]$.

Considering the large anisotropic thermal properties of $\mathrm{G}_{\mathrm{f}}(1000 \mathrm{~W} / \mathrm{m} \mathrm{K}$ in-plane [15] and 5-10 W/m K through-plane [16]), the orientation of $\mathrm{G}_{\mathrm{f}}$ in the metal matrix is vital to obtain the high overall TC along the direction of graphite plane $[6,17,18]$. High alignment of $G_{f}$ has been realized via liquid phase routes, such as gas infiltration 
and squeeze casting, because $\mathrm{G}_{\mathrm{f}}$ tends to lie on the top of each other due to its large ratio of lateral size and thickness. It is also necessary to add a separator (e.g., silicon carbide $(\mathrm{SiC})$ [19] or silicon ( $\mathrm{Si}$ ) particles [20]) to create spacing between the layers of $\mathrm{G}_{\mathrm{f}}$ making metal infiltration feasible. However, the presence of spacers may act as obstacles for heat transfer of the matrix, which is the disadvantage for the TC of composite [13]. Regarding powder metallurgy, the high orientation of $G_{f}$ was expected to be acquired by applying uniaxial compression during compacting and sintering processes $[6,21,22]$. However, it was reported that there was still some misaligned $\mathrm{G}_{\mathrm{f}}$ distributed in the Al matrix using the one-step die filling of spherical powder [14]. One possible solution to avoid misaligned $G_{f}$ was reported in $G_{f} / C u$ composite [12, 23], in which the powder loading process was divided into several steps. Alternatively, a high orientation of $\mathrm{G}_{\mathrm{f}}$ in the $\mathrm{Al}$ matrix was obtained by one-step die filling after converting the spherical Al powder into flake one using ball milling [14]. Using the flake Al powder, instead of spherical one, led to decrease of the apparent density to increase the $G_{f}$ alignment parallel to $G_{f}$ basal plane during cold compaction [24]. However, ball milling is regarded as a time consuming process, and it can probably reduce the $\mathrm{TC}$ of $\mathrm{Al}$ matrix itself by increasing oxygen content and introducing contamination compared to initial gas-atomized (spherical) powder [14].

Further, it should be emphasized that interfacial thermal resistance (ITR) between the metal matrix and reinforcement dominates the overall TC of MMCs, especially for non-wetting or non-reactive systems, such as carbon/Cu. For these composites, TC can be easily enhanced by introducing chemical bonding between the matrix and the reinforcement [11, 25-28]. When reinforced with isotropic material, such as D particles, TC is mainly determined by the intrinsic thermal properties of the matrix and the reinforcement as well as the ITR [11, 29]. However, due to the anisotropic thermal properties of $\mathrm{G}_{\mathrm{f}}$, alignment of $\mathrm{G}_{\mathrm{f}}$ should be considered as an additional factor in order to tailor the TC of composite [30]. It was reported that reduction treatment can increase intrinsic TC of as-received $G_{f}$ and, in turn, the overall TC of composite [31]. To the best knowledge of the authors, no works have dealt with the enhancement of in-plane $T C$ of the $\mathrm{G}_{\mathrm{f}} / \mathrm{Al}$ composite via improving both 
the alignment degree of $\mathrm{G}_{\mathrm{f}}$ and ITR.

The main objective of this work aimed to achieve the highest orientation of $G_{f}$ in the Al matrix via a step-by-step powder filling process using the spherical Al powder. Followed by this, the in-plane $\mathrm{TC}$ of the perfectly oriented $\mathrm{G}_{\mathrm{f}} / \mathrm{Al}$ composite can be maximized by optimizing the sintering temperature and using $\mathrm{Ar}+\mathrm{H}_{2}$ treated $\mathrm{G}_{\mathrm{f}}$, considering simultaneously the ITR and the intrinsic TC of $\mathrm{G}_{\mathrm{f}}$.

\section{Experimental}

Starting materials were gas-atomized spherical Al powder (ULTD0065, Hermillon powders, France, Fig. 1a) with the average particle size of around $10 \mu \mathrm{m}$, and $\mathrm{G}_{\mathrm{f}}$ (Purchased from Yanxin-Graphite Co., Ltd, China, Fig. 1b) with the diameter and thickness of around $500 \mu \mathrm{m}$ and $25 \mu \mathrm{m}$, respectively. A small batch of $\mathrm{G}_{\mathrm{f}}$ was treated at $400{ }^{\circ} \mathrm{C}$ under $\mathrm{Ar}+\mathrm{H}_{2}$ atmosphere $\left(95 \% \mathrm{Ar}+5 \% \mathrm{H}_{2}\right)$ for $1 \mathrm{~h}$. Al powder was mixed with $\mathrm{G}_{\mathrm{f}}$ using a resonant acoustic mixer (LabRAM, Butte, Montana, USA) for $20 \mathrm{~s}$ with an acceleration of $70 \mathrm{~g}$, in which the volume fraction of $\mathrm{G}_{\mathrm{f}}$ was fixed at $40 \%$. The mixture was filled in a graphite die step-by-step and compacted under a pressure of $2 \mathrm{MPa}$, in which the thickness of each layer was controlled thinner than $1 \mathrm{~mm}$. Cylindrical bulk composite sample $(\Phi 40 \mathrm{~mm} \times 7.5 \mathrm{~mm})$ was fabricated by vacuum hot pressing (VHP) under the vacuum of $5 \times 10^{-1}$ mbar. Uniaxial pressure and holding time were set to $60 \mathrm{MPa}$ and $30 \mathrm{~min}$, respectively. Different sintering temperatures used were $580{ }^{\circ} \mathrm{C}, 600{ }^{\circ} \mathrm{C}, 620{ }^{\circ} \mathrm{C}$, and $640{ }^{\circ} \mathrm{C}$. It should be noted that the sample sintered at $640{ }^{\circ} \mathrm{C}$ had the difficulty of demold and the risk of breaking the mold after sintering since it was easy to enwrap the punch under uniaxial pressure during sintering. Thus, the sintering temperature of $620{ }^{\circ} \mathrm{C}$ was applied to produce a composite used for CTE and mechanical property tests. For comparison, the same amount of powder mixture and pure Al was filled in the die by one single step and compacted by VHP at $620{ }^{\circ} \mathrm{C}$. Hereafter hot pressing direction and $\mathrm{G}_{\mathrm{f}}$ plane were designated as $\mathrm{z}$ direction and $\mathrm{x}-\mathrm{y}$ plane, respectively. 

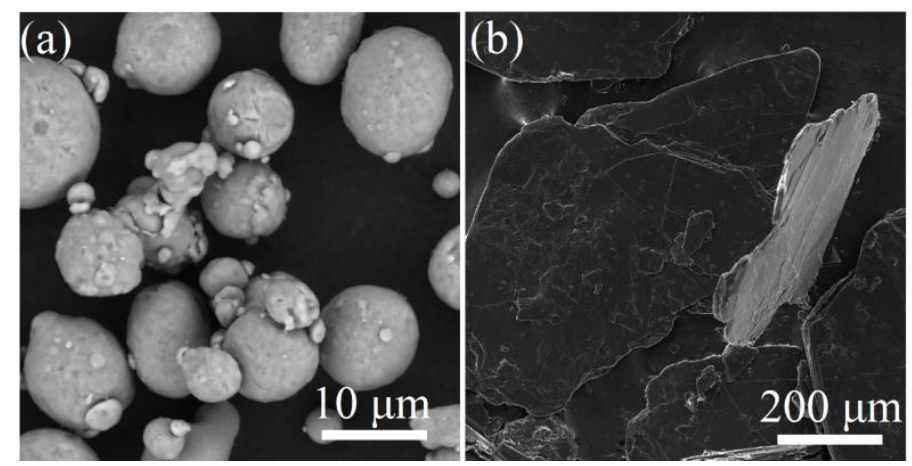

Fig. 1. SEM micrographs showing the morphologies of (a) as-received spherical Al, and (b)

$\mathrm{G}_{\mathrm{f}}$ powders.

Cross-sectional microstructures, perpendicular to $x-y$ plane, were characterized by scanning electron microscopy (SEM) using Tescan VEGA and JEOL JSM-7800F microscopes. X-ray diffraction (XRD) was carried out using a PANalytical X'pert PRO MPD diffractometer $(\mathrm{Cu} \mathrm{K} \alpha$ radiation, $\lambda=0.15418 \mathrm{~nm}) .2 \theta$ angular range and scanning speed were set to $8-80^{\circ}$ and $1 \%$ min, respectively. If necessary, low scanning rate of $0.2^{\circ} / \mathrm{min}$ in the angular range $30-38^{\circ}$ was used to detect the possible formation of aluminum carbide $\left(\mathrm{Al}_{4} \mathrm{C}_{3}\right)$. A high purity $\mathrm{Si}$ powder was used as a reference to calibrate the (002) peak position of as-received and $\mathrm{Ar}+\mathrm{H}_{2}$ treated $\mathrm{G}_{\mathrm{f}}$ for verifying their graphitization degree, where the XRD measurement was set at a low scanning rate of $0.25^{\circ} / \mathrm{min}$ in the angular range $25-30^{\circ}$. Standard Si powder with particle size in the range $25-50 \mu \mathrm{m}$ was obtained through pulverizing a single crystal of $\mathrm{Si}$ following by screening with 325 and 500 mesh standard sieves.

Both as-received and $\mathrm{Ar}+\mathrm{H}_{2}$ treated $\mathrm{G}_{\mathrm{f}}$ were characterized by Raman spectroscopy using a high-resolution Horiba spectrometer equipped with a $532 \mathrm{~nm}$ laser in a backscattering micro-configuration (accuracy equal to $0.1 \mathrm{~cm}^{-1}$ ). Laser power was kept in the range between 5 and $10 \mathrm{~mW}$. All the tests were carried out at room temperature with a $50 \times$ objective having a laser spot size of about $400 \mathrm{~nm}$. Single and multi-peak fittings of selected Raman bands were done using Gaussian and Lorentzian functions in Fityk 1.3.1 software.

Thermal diffusivity (TD) was measured at $70{ }^{\circ} \mathrm{C}$ by laser flash technique using a NETZSCH LFA 45 instrument. Relative density was calculated through dividing the experimental one measured via Archimedes principle by the theoretical one (2.52 
$\mathrm{g} / \mathrm{cm}^{3}$ ). Specific heat capacity (HC) of composite materials was calculated using the linear rule of mixture. TC of as-sintered sample was calculated by multiplying TD, density, and HC. Sample (cylinder shape with $\Phi 6 \mathrm{~mm} \times 4 \mathrm{~mm}$ ) used for TD measurement was machined along x-y plane.

Thermal expansion behaviours were examined by a horizontal dilatometer (NETZSCH DIL 402 PC) in two thermal cycles from $40{ }^{\circ} \mathrm{C}$ to $300{ }^{\circ} \mathrm{C}$ with the heating/cooling rates of $2{ }^{\circ} \mathrm{C} / \mathrm{min}$ in an argon atmosphere. Samples were cut into a cubic shape $\left(5 \times 5 \times 5 \mathrm{~mm}^{3}\right)$. Measurements were carried out along the three directions: parallel and perpendicular to the pressing direction as well as along the direction having the angle of $45^{\circ}$ with respect to the $G_{f}(x-y)$ plane.

Flexural strength of samples with a dimension of $2 \times 7 \times 40 \mathrm{~mm}^{3}$ was measured at room temperature by 3-points bending test using a universal testing instrument (Instron ${ }^{\circledR} 3369$ ). Loading rate was set to $0.01 \mathrm{~mm} / \mathrm{sec}$. Only samples in $\mathrm{X}-\mathrm{z}$ or $\mathrm{y}-\mathrm{z}$ planes were tested due to size limitation.

\section{Results and discussion}

\subsection{Effect of $\mathrm{Ar}+\mathrm{H}_{2}$ heat treatment on the $\mathbf{T C}$ of $\mathbf{G}_{\mathrm{f}}$}

Fig. 2 shows the XRD patterns of the $\mathrm{G}_{\mathrm{f}}$ and $\mathrm{Si}$ powder mixtures. The (002) peak of $\mathrm{G}_{\mathrm{f}}$ was corrected by the (111) peak of Si using the following equation [32]:

$$
2 \theta_{\mathrm{Si}}-\delta_{\mathrm{Si}-\mathrm{C}}=2 \theta_{\mathrm{C}}
$$

where $2 \theta_{\mathrm{Si}}$ is $28.443^{\circ}$ for standard Si powder. $\delta_{\mathrm{Si}-\mathrm{C}}$ of 1.892 was measured as can be seen in Fig. 2. Indeed, this value is the same for both as-received and $\mathrm{Ar}+\mathrm{H}_{2}$ treated $\mathrm{G}_{\mathrm{f}}$. Additionally, the inter-planar of $\mathrm{d}_{002}$ was calculated using Bragg's equation with $2 \theta_{\mathrm{C}}$ value originated from Eq. (2):

$$
\mathrm{d}=\lambda / 2 \sin \theta_{\mathrm{C}}
$$

The calculated $\mathrm{d}_{002}$ is $0.3357 \mathrm{~nm}$, which is very close to $0.3355 \mathrm{~nm}$ for high-quality graphite [33]. Note that the smaller $\mathrm{d}_{002}$ and the higher degree of graphitization of $\mathrm{G}_{\mathrm{f}}[34]$. Thus, the result indicates that the high graphitization degree of $\mathrm{G}_{\mathrm{f}}$ maintained unchanged after $\mathrm{Ar}+\mathrm{H}_{2}$ heat treatment at $400{ }^{\circ} \mathrm{C}$. 


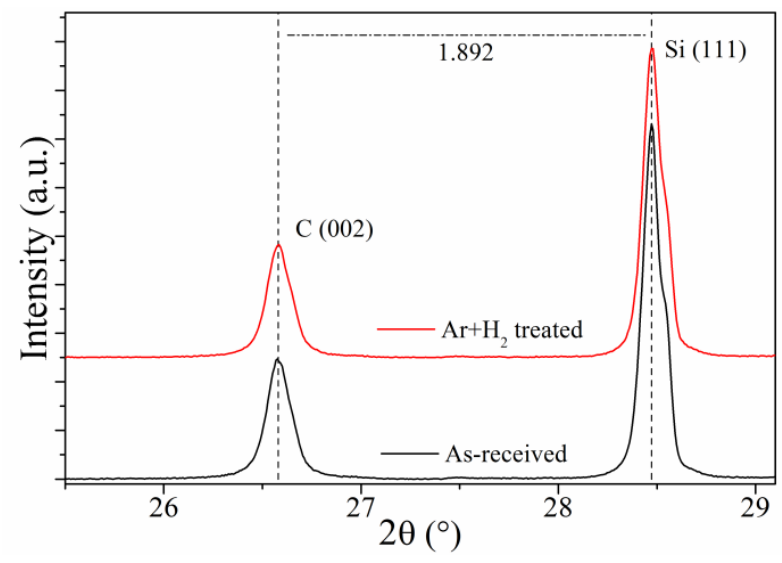

Fig. 2. XRD patterns of $\mathrm{G}_{\mathrm{f}}$ mixed with standard $\mathrm{Si}$ powder before and after reduction treatment

Fig. 3 shows the Raman spectra recorded on the edge of the as-received and Ar + $\mathrm{H}_{2}$ treated $\mathrm{G}_{\mathrm{f}}$. The $\mathrm{G}$ band appears at around $1580 \mathrm{~cm}^{-1}$ corresponding to $\mathrm{sp}^{2}-\mathrm{C}$ network. The $\mathrm{D}$ and $\mathrm{D}^{\prime}$ bands are located at around $1350 \mathrm{~cm}^{-1}$ and $1620 \mathrm{~cm}^{-1}$, respectively, which resulted from the defects in the C-lattice of $G_{f}$. The ratio $I_{D} / I_{G}$ has been applied to indicate the concentration of defects in graphite $[35,36]$. The result shows that the $\mathrm{I}_{\mathrm{D}} / \mathrm{I}_{\mathrm{G}}$ value on the edge of graphite decreases from $0.4 \pm 0.1$ to $0.2 \pm$ 0.03 after $\mathrm{Ar}+\mathrm{H}_{2}$ heat treatment, while this ratio in the center of $\mathrm{G}_{\mathrm{f}}$ is nearly independent on heat treatment and lower. Moreover, the $\mathrm{I}_{\mathrm{D}} / \mathrm{I}_{\mathrm{D}}$, value was calculated to be around 0.3 for both samples, which indicates the existing defects can be classified as boundary-like type [37]. The decrease of defects on the edge of $G_{f}$ can promote heat transport carried by phonons to improve interface thermal exchange efficiency between $\mathrm{Al}$ and $\mathrm{G}_{\mathrm{f}}$.
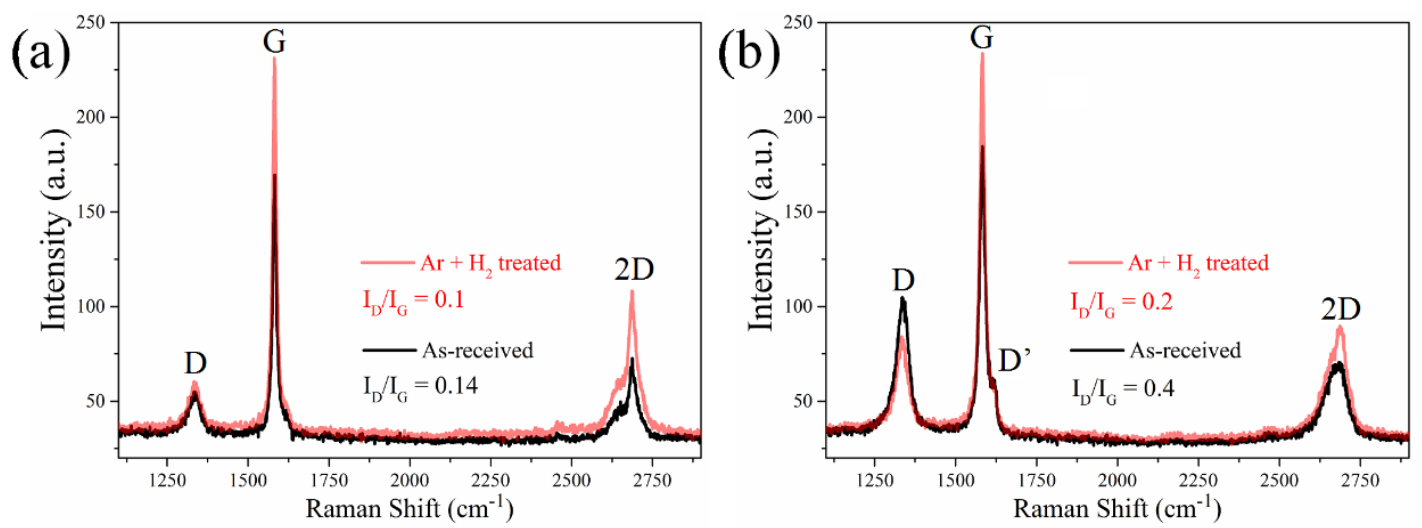

Fig. 3. Raman spectra recorded from (a) center and (b) edge areas of the as-received (black) and $\mathrm{Ar}+\mathrm{H}_{2}$ heat treated (red) $\mathrm{G}_{\mathrm{f}}$ 


\subsection{Microstructure characterization of the $G_{f} / A l$ composite materials}

Fig. 4a shows the typical cross-sectional SEM micrograph of the sintered composite applying the one-step powder filling process. The dark regions represent $\mathrm{G}_{\mathrm{f}}$, and the continuous gray region is the $\mathrm{Al}$ matrix. Most of $\mathrm{G}_{\mathrm{f}}$ were oriented along the $\mathrm{x}-\mathrm{y}$ plane, while there are still quite a few $\mathrm{G}_{\mathrm{f}}$ distributed randomly (some even were oriented along the $\mathrm{z}$ (pressing) direction). Consistent with the previous results in Ref.[14], the application of uniaxial pressure can result in the alignment of $G_{f}$ during hot pressing [6], but it is insufficient to achieve the high orientation of $\mathrm{G}_{\mathrm{f}}$. Comparatively, the perfectly high alignment of $\mathrm{G}_{\mathrm{f}}$ was obtained using the step-by-step powder filling process as shown in Fig. 4 b. Importantly, the misalignment of $G_{f}$ was effectively avoided by controlling the thickness of each layer when filling the powder.
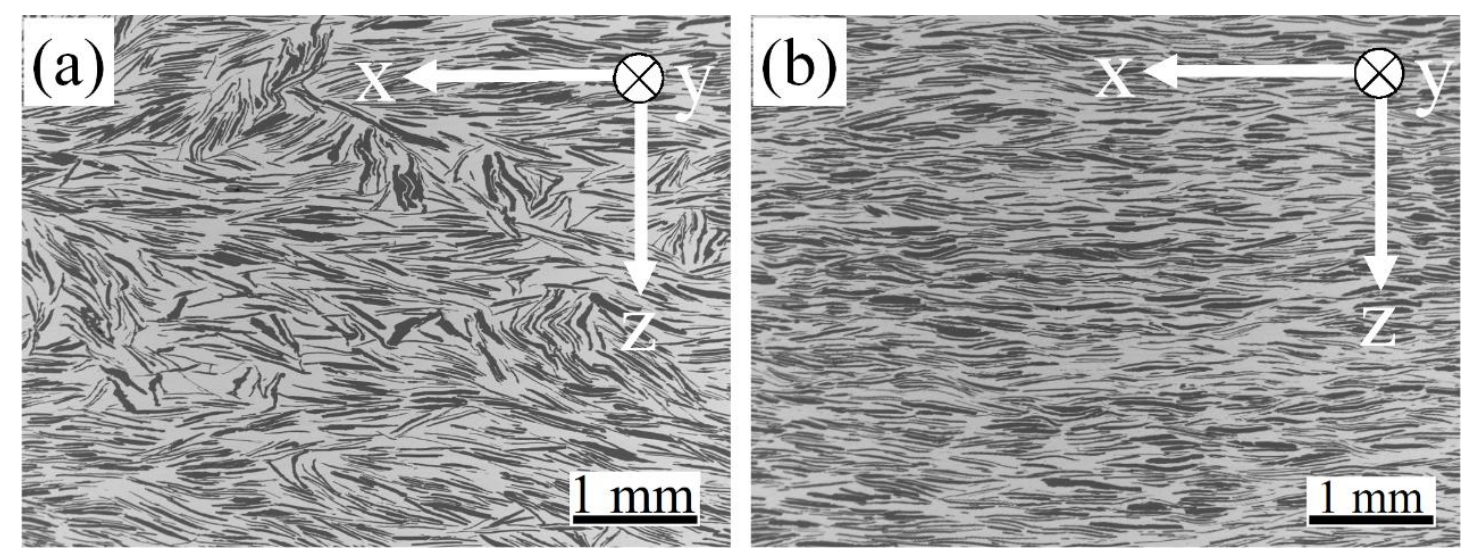

Fig. 4. Typical SEM micrographs of the 40 vol. $\% \mathrm{G}_{\mathrm{f}} / \mathrm{Al}$ composite materials sintered at $620^{\circ} \mathrm{C}$ using (a) one-step, (b) step-by-step powder filling methods.

The XRD results (Fig. 5) of the $\mathrm{G}_{\mathrm{f}} / \mathrm{Al}$ composites sintered at the different temperatures show qualitatively the similar diffraction peaks of $\mathrm{Al}$ and $\mathrm{G}_{\mathrm{f}}$. No peaks corresponding to $\mathrm{Al}_{4} \mathrm{C}_{3}$ (see inset in Fig. 5) are confirmed even at the highest temperature of $640{ }^{\circ} \mathrm{C}$. In addition, the diffraction peak at about $2 \theta=26.5^{\circ}$, corresponding to (002) crystal plane of hexagonal graphite, has the relatively weak intensity indicating the high orientation arrangement of $\mathrm{G}_{\mathrm{f}}[13]$. 


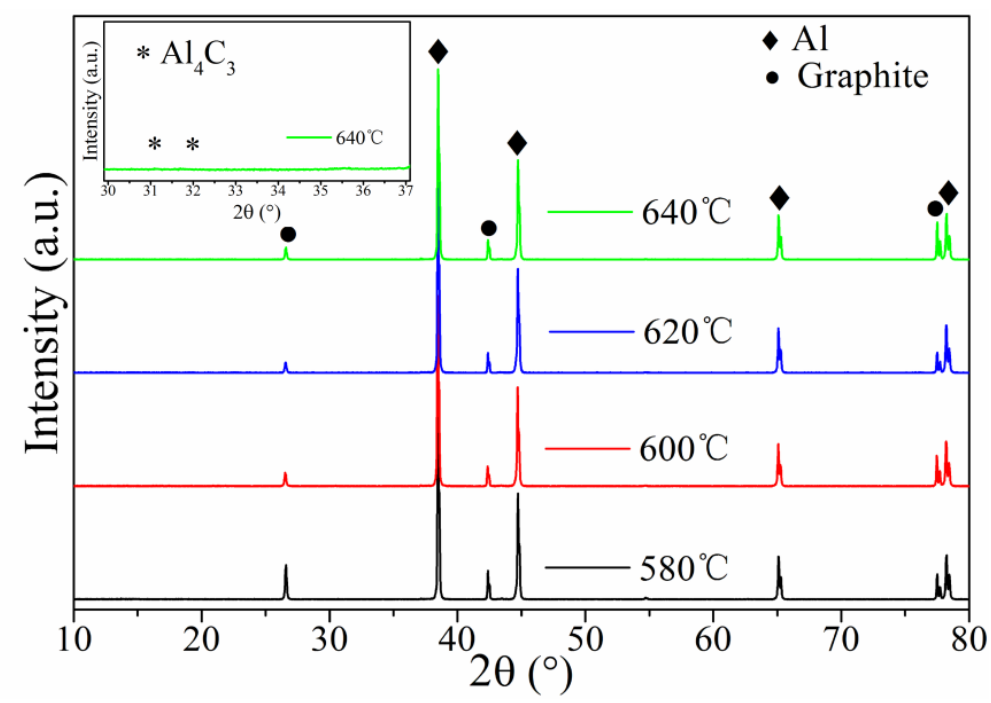

Fig. 5. XRD patterns of the $\mathrm{G}_{\mathrm{f}} / \mathrm{Al}$ composite samples sintered at the different temperatures

High-magnified SEM micrographs (Fig. 6) clearly show that there are no defects like pores at the side surface $\mathrm{G}_{\mathrm{f}} / \mathrm{Al}$ interface (i.e. interface perpendicular to the direction for TC measurement), and visibly more platelet-like phases distributed at the interface of the composite sintered at $640{ }^{\circ} \mathrm{C}$ than sintered at $580{ }^{\circ} \mathrm{C}$. It has been well-known that $\mathrm{Al}_{4} \mathrm{C}_{3}$ is the most common interfacial reaction product [38-40], where the chemical reaction can be described as follows: $4 \mathrm{Al}+3 \mathrm{C} \rightarrow \mathrm{Al}_{4} \mathrm{C}_{3}$. The standard free energy of reaction can be given by $\Delta \mathrm{G}=-289,512+60 \times \mathrm{T}$ ( $\mathrm{T}$ is the temperature) [41], indicating there is always a tendency of the formation of $\mathrm{Al}_{4} \mathrm{C}_{3}$ at the interface as the free energy is negative in the large temperature range. Thus, the platelet-like phases should be the reactive product $\left(\mathrm{Al}_{4} \mathrm{C}_{3}\right)$ of $\mathrm{Al}$ and $\mathrm{G}_{\mathrm{f}}$. Moreover, the reaction rate of $\mathrm{Al}_{4} \mathrm{C}_{3}$ is determined by atomic diffusion, which can be calculated by the equation $X=(2 \mathrm{Kt})^{1 / 2}$, where $\mathrm{X}$ represents the thickness of the reaction layer and $\mathrm{t}$ is the reaction time, $\mathrm{K}$ is the reaction rate constant which is associated with temperature [42]. It suggests that increasing processing temperature and time can lead to more formation of $\mathrm{Al}_{4} \mathrm{C}_{3}$. In this case, increase of sintering temperature can result in more creation of interfacial product meaning more chemical bonding formed between the $\mathrm{Al}$ matrix and $\mathrm{G}_{\mathrm{f}}$ reinforcement. Our previous studies by in-depth electron microscopy characterization indicate that suitable formation of $\mathrm{Al}_{4} \mathrm{C}_{3}$ at the nanoscale can effectively minimize ITR being highly beneficial for improving overall TCs of the D/Al [43] and $\mathrm{G}_{\mathrm{f}} / \mathrm{Al}$ composites [20]. 

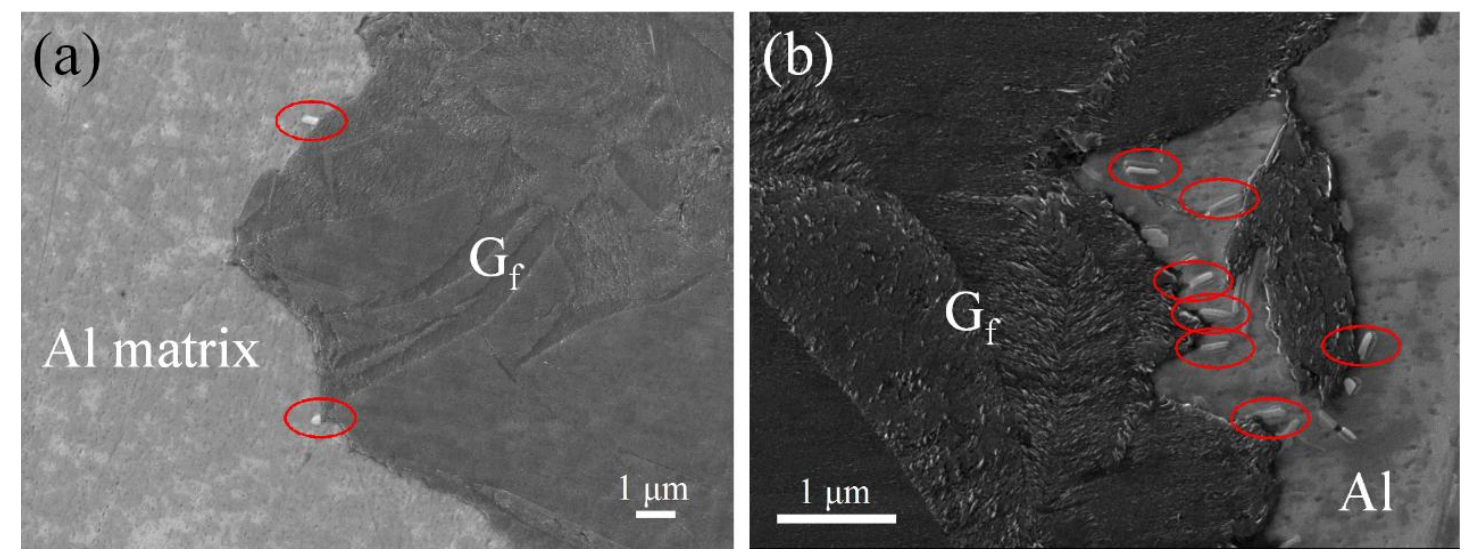

Fig. 6. SEM micrographs of the $\mathrm{Al} / 40$ vol. $\% \mathrm{G}_{\mathrm{f}}$ (as-received) composites highlighting the Al- $\mathrm{G}_{\mathrm{f}}$ interface area in the samples sintered at the different temperatures of (a) $580{ }^{\circ} \mathrm{C}$ and (b) $640{ }^{\circ} \mathrm{C}$.

\subsection{Discussion of theoretical TC by numerical calculations}

The various factors affecting the TC of MMC include the intrinsic thermal properties of matrix and reinforcement, the shape, size, orientation and volume fraction of reinforcement, and the ITR. There is a classical model that considers all of those factors called effective medium approximation (EMA) [44]. The formulation of in-plane TC is defined as follows:

$$
\mathrm{K}_{/ /}=\mathrm{K}_{\mathrm{m}} \frac{2+\mathrm{f}\left[\beta_{\mathrm{L}}\left(1-\mathrm{S}_{\mathrm{L}}\right)\left(1+\left\langle\cos ^{2} \theta\right\rangle\right)+\beta_{\mathrm{T}}\left(1-\mathrm{S}_{\mathrm{T}}\right)\left(1-\left\langle\cos ^{2} \theta\right\rangle\right)\right]}{2-\mathrm{f}\left[\beta_{\mathrm{L}} \mathrm{S}_{\mathrm{L}}\left(1+\left\langle\cos ^{2} \theta\right\rangle\right)+\beta_{\mathrm{T}} \mathrm{S}_{\mathrm{T}}\left(1-\left\langle\cos ^{2} \theta\right\rangle\right)\right]}
$$

in which

$$
\begin{gathered}
\left\langle\cos ^{2} \theta\right\rangle=\frac{\int \rho(\theta) \cos ^{2} \theta \sin \theta d \theta}{\int \rho(\theta) \sin \theta d \theta} \\
\beta_{i}=\frac{K_{i}-K_{m}}{K_{m}+S_{i}\left(K_{i}-K_{m}\right)}, \quad(i=L, T) \\
S_{L}=\frac{\pi t}{4 D}, \quad S_{T}=1-\frac{\pi t}{2 D}
\end{gathered}
$$

The subscripts $L$ and $T$ are noted as the in-plane and through-plane directions of $G_{f}$, respectively. $\mathrm{f}$ is the volume fraction of reinforcement, and $\mathrm{S}$ is the geometrical factor, where $\mathrm{D}$ and $\mathrm{t}$ are the diameter and thickness of the reinforcement, respectively [14]. $\mathrm{K}_{\mathrm{m}}$ is the TC of the Al matrix, which obtained from the measured TC of the pure Al sample $(220 \pm 2 \mathrm{~W} / \mathrm{m} \mathrm{K}) . \mathrm{K}_{\mathrm{i}}$ is intrinsic $\mathrm{TC}$ of $\mathrm{G}_{\mathrm{f}}$, and $\mathrm{K}_{\mathrm{L}}$, and $\mathrm{K}_{\mathrm{T}}$ are 1000 [6], and $10 \mathrm{~W} \mathrm{~m} \mathrm{~m}^{-1} \mathrm{~K}^{-1}$ [45], respectively. $\left\langle\cos ^{2} \theta\right\rangle$ represents the alignment degree of reinforcements in the matrix, where $\rho(\theta)$ is a distribution function describing the orientation of $\mathrm{G}_{\mathrm{f}}$ in $\mathrm{Al}$ matrix. $\theta$ is the angle between the basic graphite plane and the 
$\mathrm{x}-\mathrm{y}$ plane of the composite materials.

Image analysis technique $[18,46]$ was used to statistically calculate the angle $\theta$ distribution of $\mathrm{G}_{\mathrm{f}}$. The result of the statistical measurement of angle $\theta$ by Image $\mathrm{J}$ software based on Fig. 4 is shown in Fig. 7, in which it contains the fittings of angle distribution. Herein, an ExpDec 1 function $\varphi(\theta)$ was used to fit the curves of the frequency (the number of $G_{f}$ at certain $\theta$ in all the $G_{f}$ ) versus $\theta$ using Origin software $[46,47]$.

$$
\varphi(\theta)=\mathrm{A}_{1} \mathrm{e}^{\left(-\theta / \mathrm{t}_{1}\right)}+\mathrm{y}_{0}
$$

where $A_{1}, t_{1}$ and $y_{0}$ are the fitting variables. After applying the fittings, the specific $\varphi(\theta)$ was obtained, and $\left\langle\cos ^{2} \theta\right\rangle$ values of each considered image can be calculated through numerical integration. It shows that $\left\langle\cos ^{2} \theta\right\rangle$ values of all the samples except the one (Fig. 7a) using the one-step powder filling are close to 0.94, suggesting that they have almost the same orientation of $\mathrm{G}_{\mathrm{f}}$. Indeed, the same alignment level of $G_{f}$ has been achieved in the $G_{f} / A l$ composite using the flake $A l$ powder associated with step-by-step powder filling method [48]. Therefore, it confirms that such a step-by-step powder filling method can achieve the high orientation of $\mathrm{G}_{\mathrm{f}}$ in the $\mathrm{Al}$ matrix no matter which type of $\mathrm{Al}$ powders used.
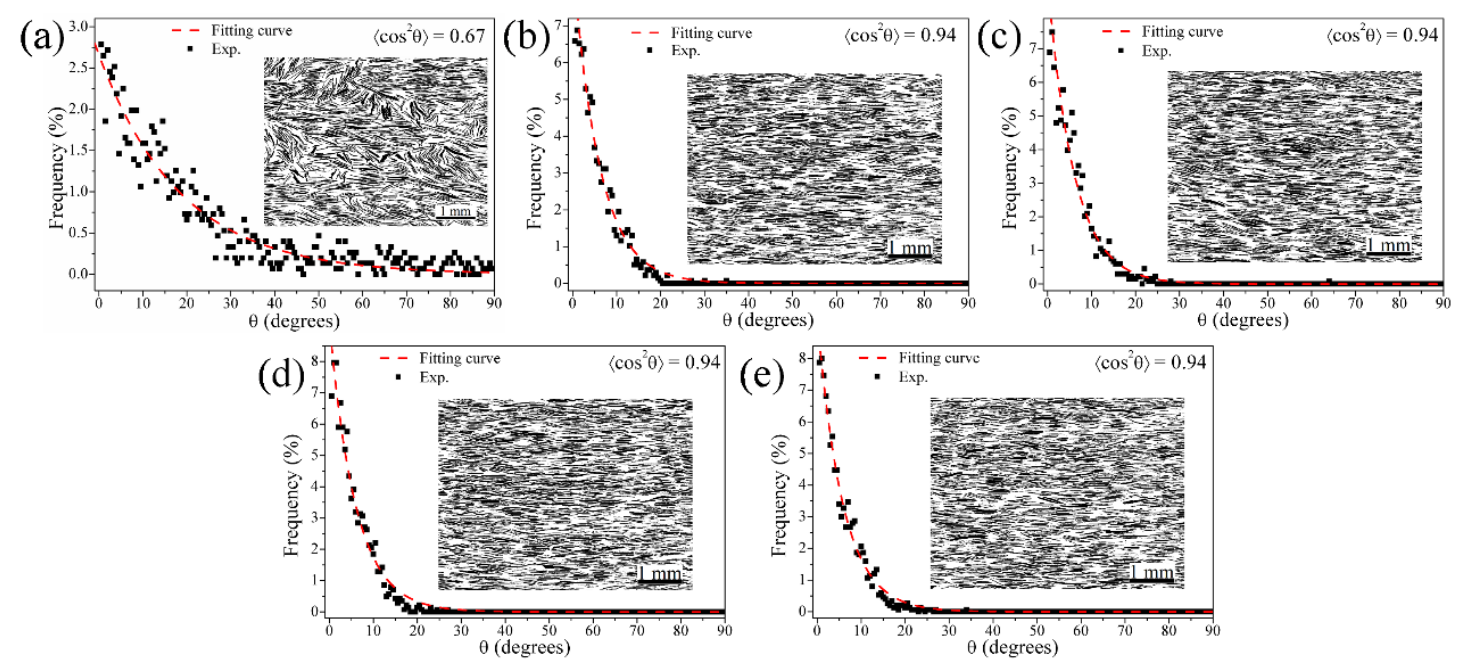

Fig. 7. Distribution plots of the angle between the graphite basic plane and the $x-y$ plane of the composites sintered at the different temperatures, (a) $620{ }^{\circ} \mathrm{C}$ fabricated by one-step powder filling; (b) $580{ }^{\circ} \mathrm{C}$, (c) $600{ }^{\circ} \mathrm{C}$, (d) $620^{\circ} \mathrm{C}$, (e) $640{ }^{\circ} \mathrm{C}$ fabricated by step-by-step powder filling, plots were fitted by the 'nonlinear curve fit' process using Origin software.

In order to consider interfacial thermal conductance (ITC, inversely proportional 
to ITR), interfacial thermal barrier was introduced via making modification of the intrinsic TC of reinforcement [49]. Therefore, the TC of filler can be treated as an effective TC, and equations are expressed as follows:

$$
\begin{aligned}
\mathrm{K}_{\mathrm{L}}^{\text {eff }} & =\frac{\mathrm{K}_{\mathrm{L}}}{\frac{2 \mathrm{~K}_{\mathrm{L}}}{\mathrm{hD}}+1} \\
\mathrm{~K}_{\mathrm{T}}^{\text {eff }} & =\frac{\mathrm{K}_{\mathrm{T}}}{\frac{2 \mathrm{~K}_{\mathrm{T}}}{\mathrm{ht}}+1}
\end{aligned}
$$

Where $\mathrm{h}$ is the ITC, which can be acquired using the acoustic mismatch model (AMM) [50]. $\mathrm{h}_{\mathrm{AMM}}$ is expressed to be:

$$
\mathrm{h}_{\mathrm{AMM}} \cong \frac{1}{2} \rho_{\mathrm{m}} \mathrm{C}_{\mathrm{m}} \frac{v_{\mathrm{m}}^{3}}{v_{\mathrm{r}}^{2}} \frac{\rho_{\mathrm{m}} v_{\mathrm{m}} \rho_{\mathrm{r}} v_{\mathrm{r}}}{\left(\rho_{\mathrm{m}} v_{\mathrm{m}}+\rho_{\mathrm{r}} v_{\mathrm{r}}\right)^{2}}
$$

where $\mathrm{C}, \rho$, and $\mathrm{v}$ are the specific heat capacity, density and the Debye phonon velocity, respectively, and subscripts $\mathrm{m}$ and $\mathrm{r}$ represent the matrix and reinforcement, respectively. The values of these material parameters can be obtained from previous work [14]. The ITC of $\mathrm{G}_{\mathrm{f}} / \mathrm{Al}$ composite material was thus calculated using equation (8) is $4.6 \times 10^{7} \mathrm{~W} \mathrm{~m}^{-2} \mathrm{~K}^{-1}$.

Fig. 8 shows the TC predictions as the dependence of various factors based on EMA model, which helps to better understand how to tailor the TC of composites. Volume fraction of $\mathrm{G}_{\mathrm{f}}$ is a remarkable parameter that affects the overall TC of composite, which has been investigated in details in refs. $[6,14]$. As mentioned above, $\mathrm{G}_{\mathrm{f}}$ is a highly anisotropic material such that the orientation is very critical to the enhancement of TC along the basal plane of graphite. Thus, if being highly oriented along the in-plane direction of $G_{f}$, TC of composites goes up with increment of $G_{f}$ content as shown in Fig. 8a.

In order to study the evolution of TC as a function of ITC $(h)$ at the given volume fraction of $\mathrm{G}_{\mathrm{f}}$, the variable $h$ can be expressed as $4.6 \times 10^{\mathrm{x}} \mathrm{W} \mathrm{m}^{-2} \mathrm{~K}^{-1}$, where $\mathrm{x}$ is $\mathrm{Lg}(\mathrm{h} / 4.6)$ ( $\mathrm{Lg}$ is common logarithm). When the volume fraction of $\mathrm{G}_{\mathrm{f}}$ is set to 40 vol.\%, the theoretical predication of $\mathrm{TC}$ as a function of the $\operatorname{Lg}(\mathrm{h} / 4.6)$ with the different orientation degrees is shown in Fig. 8b using equation (1). It indicates that there is the quick change of $\mathrm{TC}$ in the $\mathrm{Lg}(\mathrm{h} / 4.6)$ range 5-7, while the $\mathrm{TC}$ becomes maximum and constant when the $\operatorname{Lg}(\mathrm{h} / 4.6)$ is larger than 8. It should be highlighted that the TC does not reach the maximum value when $\mathrm{h}$ is $4.6 \times 10^{7} \mathrm{~W} \mathrm{~m}^{-2} \mathrm{~K}^{-1}$ 
obtained using AMM as shown by a vertical dotted line in Fig. 8b. On the other hand, when we modified the intrinsic TC of $\mathrm{G}_{\mathrm{f}}$ in the range $900-1100 \mathrm{~W} / \mathrm{m} \mathrm{K}$ at the fixed volume fraction and orientation degree of $\mathrm{G}_{\mathrm{f}}$, as shown in Fig. 8c, the maximum TC goes up as increasing the intrinsic $\mathrm{TC}$ of $\mathrm{G}_{\mathrm{f}}$. Therefore, at the given volume fraction and orientation degree of $\mathrm{G}_{\mathrm{f}}$, the intrinsic $\mathrm{TC}$ of reinforcement determines the maximum value of TC, and whether it can reach the maximum depending on the $h$.

(a)

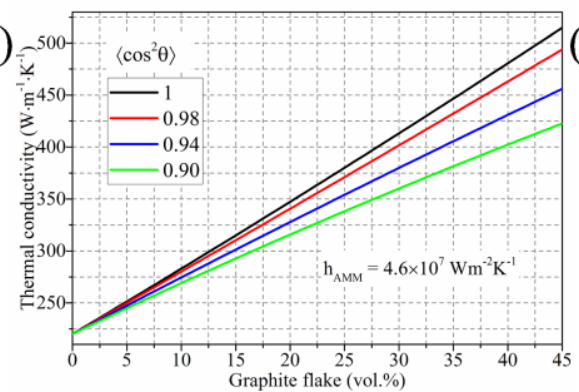

(c)

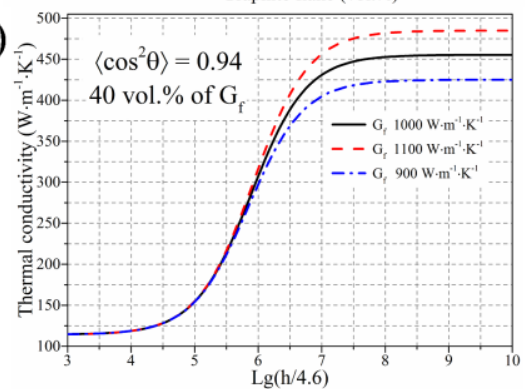

(b)

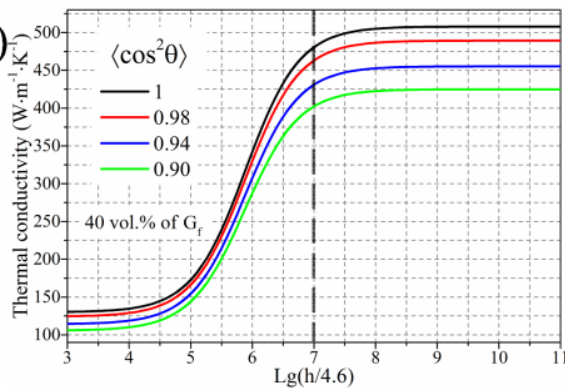

(d)

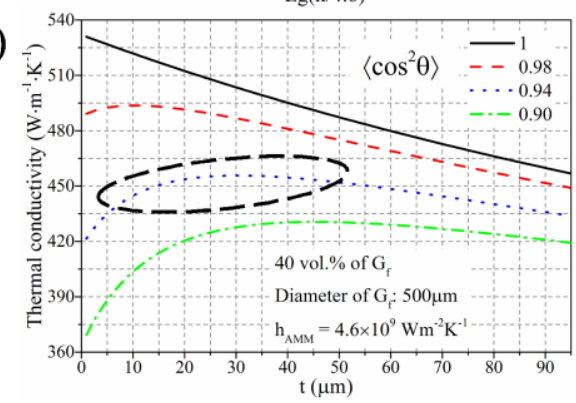

Fig. 8. Predictions of $\mathrm{TC}$ of $\mathrm{G}_{\mathrm{f}} / \mathrm{Al}$ composite as a function of (a) volume fraction of $\mathrm{G}_{\mathrm{f}}$ and (b)

ITC using 4 different orientation degrees of $G_{f}$, (c) ITC using 3 different intrinsic TCs of $G_{f}$ and (d) thickness of $\mathrm{G}_{\mathrm{f}}$ using 4 different orientation degrees of $\mathrm{G}_{\mathrm{f}}$.

The effect of $G_{f}$ thickness $t$ (the diameter of $G_{f}$ is fixed at $500 \mu \mathrm{m}$ ) on TC is illustrated in Fig. 8d, in which the volume fraction of $\mathrm{G}_{\mathrm{f}}$ is 40 vol.\%. When the alignment of $G_{f}$ is perfect, TC increases with reducing thickness of $G_{f}$. The maximum TC is around $530 \mathrm{~W} / \mathrm{mK}$ when the thickness is thinner than $1 \mu \mathrm{m}$, while the maximum TC moves slightly rightward as the orientation degree of $G_{f}$ degrades from 1 to 0.9 . In this work, the average diameter and thickness of $\mathrm{G}_{\mathrm{f}}$ are $500 \mu \mathrm{m}$ and $25 \mu \mathrm{m}$, respectively, and the orientation degree of $\mathrm{G}_{\mathrm{f}}$ is 0.94 , whose corresponding TC values is very close to the maximum one as indicated by the black ellipse in Fig. 8d. Thus, the theoretical analysis suggests that the intrinsic TC of the matrix and reinforcements need to be as high as possible to get high in-plane $T C$ of the $G_{f} / A l$ composites. Followed by this, the highly oriented $\mathrm{G}_{\mathrm{f}}$ is the most critical to obtain a high in-plane 
TC providing that the interface state between the matrix and reinforcement can be tailored to have high ITC.

\subsection{Discussion of TC using experimental results}

Fig. 9a shows the measured in-plane TCs of the 40 vol.\% $\mathrm{G}_{\mathrm{f}} / \mathrm{Al}$ composite materials sintered at the different temperatures using the as-received and $\mathrm{Ar}+\mathrm{H}_{2}$ treated $\mathrm{G}_{\mathrm{f}}$. The TCs of the samples fabricated using the step-by-step powder loading method increase with the sintering temperature. Besides, the TCs of the samples sintered at each temperature using the $\mathrm{Ar}+\mathrm{H}_{2}$ treated $\mathrm{G}_{\mathrm{f}}$ are always higher than those without such a treatment. However, this variation of TC becomes negligible at $640{ }^{\circ} \mathrm{C}$. As presented above, our step-by-step powder loading method leads to the relatively high orientation degree $\left(<\cos ^{2} \theta>\right)$ of $\mathrm{G}_{\mathrm{f}}$ of around 0.94 . For comparison, the sample fabricated via the one-step powder filling process at $620^{\circ} \mathrm{C}$ has a TC of $330 \pm 45$ $\mathrm{W} / \mathrm{m} \mathrm{K}$ (see Fig. 9a), which is much lower than the TC of the sample using the step-by-step loading method $(440 \pm 2 \mathrm{~W} / \mathrm{m} \mathrm{K})$. The low orientation degree of $\mathrm{G}_{\mathrm{f}}$ in this sample was 0.67 (Fig. 7a), which can explain the low in-plane TC, and the large error of TC also witnesses the inhomogeneous distribution of $G_{f}$. Besides, Fig. $9 b$ shows that all the sintered samples have the high relative density close to $99 \%$ suggesting that this sintering temperature variation has no significant effect on the final density. Since all the other parameters supposed to be the same considering the EMA model, such as starting materials, volume fraction and alignment degree of $\mathrm{G}_{\mathrm{f}}$, there is only one possible factor that may affect the TC of composites fabricated at the different sintering temperatures, which can be the ITC.
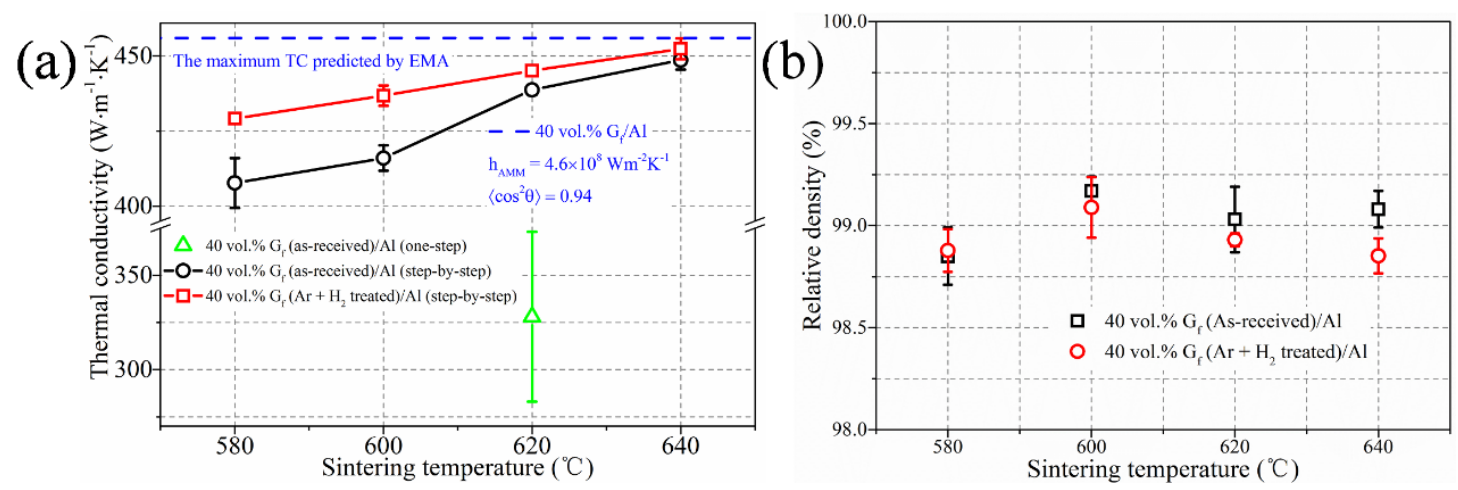

Fig. 9. (a) Measured TC values along the alignment direction and (b) relative densities of the

40 vol. $\% \mathrm{G}_{\mathrm{f}} / \mathrm{Al}$ composites produced using the step-by-step powder filling method sintered at 
the different temperatures with as-received and $\mathrm{Ar}+\mathrm{H}_{2}$ treated $\mathrm{G}_{\mathrm{f}}$.

Adrien et al. [31] reported that the intrinsic TC and surface quality of $\mathrm{G}_{\mathrm{f}}$ can be improved by heat treatment under $\mathrm{Ar}+\mathrm{H}_{2}$ atmosphere that have been confirmed by $\mathrm{XRD}$ and X-ray photoelectron spectroscopy. Thus, the overall $\mathrm{TC}$ of $\mathrm{G}_{\mathrm{f}} / \mathrm{Cu}$ composite was increased using the treated $\mathrm{G}_{\mathrm{f}}$. Being consistent with this, our results have shown increased TC of the $\mathrm{G}_{\mathrm{f}} / \mathrm{Al}$ composite using $\mathrm{Ar}+\mathrm{H}_{2}$ treated $\mathrm{G}_{\mathrm{f}}$ compared with the counterparts only using as-received $\mathrm{G}_{\mathrm{f}}$. The improved $\mathrm{TCs}$ of the $\mathrm{G}_{\mathrm{f}} / \mathrm{Al}$ composite via increasing sintering temperature suggest that ITC increases as increasing sintering temperature. However, this prediction was not reflected on the experimental results when the sintering temperature is $640{ }^{\circ} \mathrm{C}$ (Fig. 9a). Our Raman spectra and measurement of $\mathrm{d}_{002}$ of $\mathrm{G}_{\mathrm{f}}$ indicate that $\mathrm{Ar}+\mathrm{H}_{2}$ heat treatment decreases the defects of $\mathrm{G}_{\mathrm{f}}$ on the edge rather than leading to the enhancement of its intrinsic TC. One explanation is that $\mathrm{Ar}+\mathrm{H}_{2}$ treatment only helps to improve ITC rather than intrinsic TC of $\mathrm{G}_{\mathrm{f}}$, which make the similar contribution compared to increased sintering temperature. Finally, the in-plane TC almost reaches its maximum value using our fabrication conditions with the spherical Al powder (Fig. 9a).

\subsection{Thermal expansion behaviors and mechanical property}

Typical thermal expansion curves of the 40 vol. $\% \mathrm{G}_{\mathrm{f}} / \mathrm{Al}$ composites are shown in Fig. 10a, which originated from the first cooling stage. The curve (dotted line) is linear along the basal plane direction, while it (dash-dotted line) is nonlinear along the through-plane (i.e. pressing) directions. The nonlinear curves look like a parabola, which means the tested materials shrink first and then expand with continually increasing the temperature. Besides, the curve (dashed line in Fig. 10a) obtained along the direction forming an angle of $45^{\circ}$ to the basal plane also appear like a parabola, which only show that the starting points of the expansion stage shift to the low temperature ranges compared to that along the through-plane direction. 

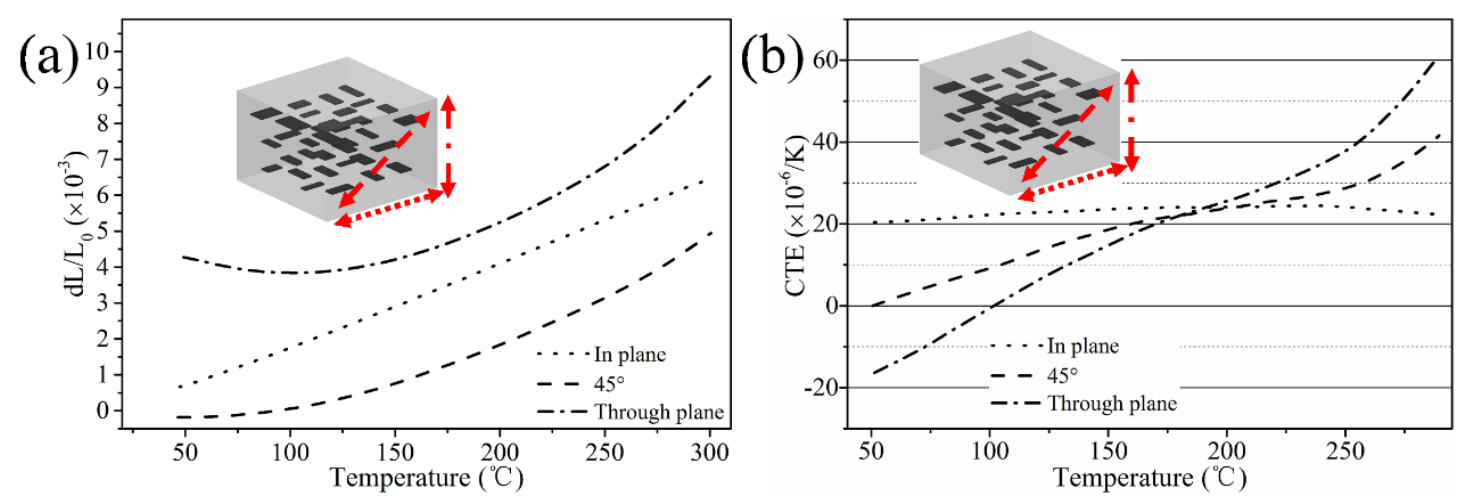

Fig. 10. (a) Thermal expansion curves and (b) dynamic CTE of the 40 vol.\% $\mathrm{G}_{\mathrm{f}} / \mathrm{Al}$ composites sintered at $620^{\circ} \mathrm{C}$ (The insets show the measuring directions).

Since through-plane thermal expansion behaviour is nonlinear, it is necessary to study the dynamic CTE $\left(\mathrm{D}_{\mathrm{CTE}}\right)$ as a function of temperature, which is the derivation of thermal expansion curve. Fig. 10b shows the $\mathrm{D}_{\mathrm{CTE}}$ curves that derived from Fig. 10a. The $\mathrm{D}_{\mathrm{CTE}}$ value is almost constant over the whole testing temperature range (40-300 ${ }^{\circ} \mathrm{C}$ ) along the direction of the basal plane (dotted line). Measured parallel to the pressing direction, $\mathrm{D}_{\mathrm{CTE}}$ varies from the low value to high one. As for the $45^{\circ}$ direction, it has an average performance of the other two directions, which can be confirmed by the calculation process using strain transformation equation. Thus, the material shows a high anisotropy in thermal expansion. It has recently been demonstrated that the architecture design by extending 1D to $2 \mathrm{D}$ arrangement can effectively tailoring CTE and maintaining the high TC [48].

The measured bending strength of the $\mathrm{Al}$ sample is $179 \mathrm{MPa}$ at $5 \%$ strain as shown in Fig. 11, while the bending strength of the composite decreased to $74 \mathrm{MPa}$. It indicates the presence of $\mathrm{G}_{\mathrm{f}}$ degraded the overall mechanical properties remarkably. Thus, how to enhance the mechanical property of the $G_{f} / A l$ composite is still a challenge in order to realize its application in microelectronic industry. Adding a small amount of nano-particles, such as $\mathrm{SiC}$, titanium diboride $\left(\mathrm{TiB}_{2}\right)$ and boron carbide $\left(\mathrm{B}_{4} \mathrm{C}\right)$, into the $\mathrm{Al}$ matrix can be effective to improve mechanical properties of composite without degrading TC of the Al matrix. The key challenge of this method is how to obtain a uniform distribution of nano-particles in the metallic matrix to make Orowan strengthening mechanism effective. Another method is architecture design based on a mimic biological structure, such as lamellar structure in nacre. Flake 
powder metallurgy applying on the $\mathrm{Al}$ powder with native $\mathrm{Al}_{2} \mathrm{O}_{3}$ skins was a simple and quick approach to produce $\mathrm{Al}_{2} \mathrm{O}_{3} / \mathrm{Al}$ nanolaminated composites with improved mechanical properties [51].

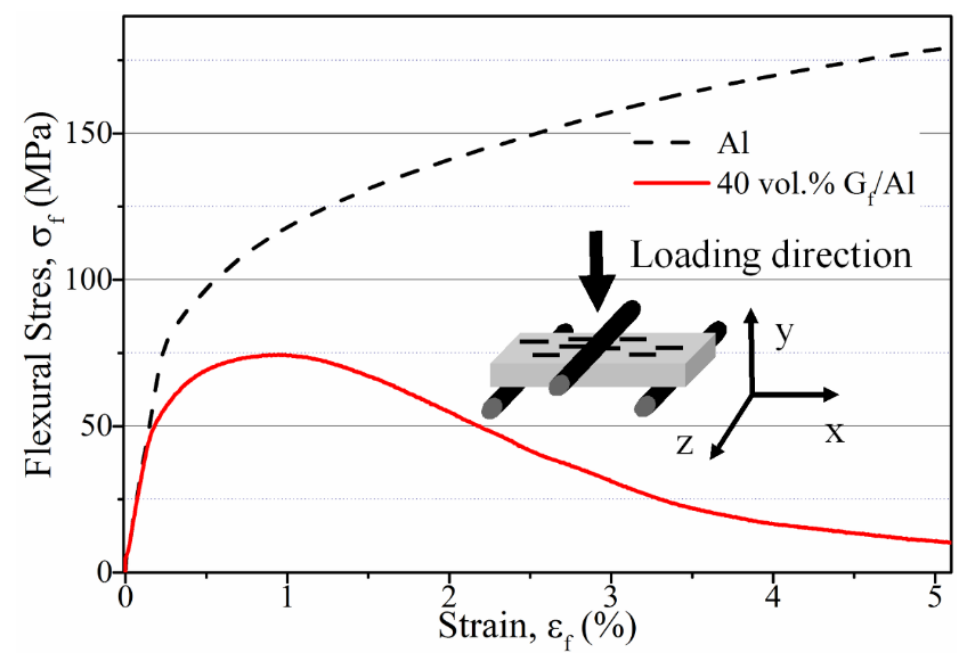

Fig. 11. Flexural stress strain curves of pure $\mathrm{Al}$ specimen and 40 vol.\% $\mathrm{G}_{\mathrm{f}} / \mathrm{Al}$ composites sintered at $620{ }^{\circ} \mathrm{C}$ (inset shows the testing direction).

\section{Conclusions}

The $G_{f} / A l$ composite materials with the perfectly high alignment of $G_{f}$ was successfully produced using the spherical Al powder via a step-by-step powder filling method, which is comparable to that by means of flake powder metallurgy [14]. Increase of the sintering temperature of VHP from $580{ }^{\circ} \mathrm{C}$ to $640{ }^{\circ} \mathrm{C}$ is able to improve the TC. Using $\mathrm{Ar}+\mathrm{H}_{2}$ heat treated $\mathrm{G}_{\mathrm{f}}$ further enhances $\mathrm{TC}$ at the same sintering temperature, while this enhancement becomes limited at the highest sintering temperature of $640{ }^{\circ} \mathrm{C}$. With the aid of EMA model, the effect of various factors on TC, such as geometry of filler, ITC between Al matrix and $\mathrm{G}_{\mathrm{f}}$, and intrinsic TC of filler, was established. The positive effects of both increasing sintering temperature and use of treated $\mathrm{G}_{\mathrm{f}}$ on $\mathrm{TC}$ of the composite materials can be attributed to the optimization of the ITC between the Al matrix and $G_{f}$. Regarding this, suitable chemical bonding by local formation of fine platelet-like $\mathrm{Al}_{4} \mathrm{C}_{3}$ at the $\mathrm{G}_{\mathrm{f}} / \mathrm{Al}$ interface is beneficial for TC enhancement. Above all, the theoretically predicted highest value of TC $(452 \mathrm{~W} / \mathrm{m} \cdot \mathrm{K})$ was experimentally obtained using the content of $\mathrm{G}_{\mathrm{f}}$ of 40 vol. $\%$. 


\section{Acknowledgments}

Zhengyan Shen's Ph.D. thesis was financially supported by the China scholarship council (Grant No. 201606890034), University of Bordeaux, and Centre National de la Recherche Scientifique (CNRS). The SEM facility (JEOL JSM-7800F) in Lille (France) is supported by the Conseil Régional du Nord-Pas de Calais, and the European Regional Development Fund (ERDF).

\section{References}

[1] C. Zweben, Advances in composite materials for thermal management in electronic packaging, 1998.

[2] D.D.L. Chung, Materials for thermal conduction. Appl. Therm. Eng. , 21 (2001) 1593-1605.

[3] R. Arpón, J.M. Molina, R.A. Saravanan, C. García-Cordovilla, E. Louis, J. Narciso, Thermal expansion behaviour of aluminium/ $\mathrm{SiC}$ composites with bimodal particle distributions. Acta Mater. , 51 (2003) 3145-3156.

[4] J.M. Molina, J. Narciso, L. Weber, A. Mortensen, E. Louis, Thermal conductivity of Al-SiC composites with monomodal and bimodal particle size distribution. Materials Science and Engineering: A, 480 (2008) 483-488.

[5] R. Prieto, J.M. Molina, J. Narciso, E. Louis, Fabrication and properties of graphite flakes/metal composites for thermal management applications. Scr. Mater., 59 (2008) 11-14.

[6] J.K. Chen, I.S. Huang, Thermal properties of aluminum-graphite composites by powder metallurgy. Composites Part B: Engineering, 44 (2013) 698-703.

[7] I. Firkowska, A. Boden, B. Boerner, S. Reich, The Origin of High Thermal Conductivity and Ultralow Thermal Expansion in Copper-Graphite Composites. Nano Lett. , 15 (2015) 4745-4751.

[8] Z. Tan, Z. Li, G. Fan, X. Kai, G. Ji, L. Zhang, D. Zhang, Fabrication of diamond/aluminum composites by vacuum hot pressing: Process optimization and thermal properties. Composites Part B: Engineering, 47 (2013) 173-180.

[9] G. Lalet, H. Kurita, J.-M. Heintz, G. Lacombe, A. Kawasaki, J.-F. Silvain, Thermal expansion coefficient and thermal fatigue of discontinuous carbon fiber-reinforced copper and aluminum matrix composites without interfacial chemical bond. Journal of Materials Science, 49 (2013) 397-402.

[10] H. Kurita, E. Feuillet, T. Guillemet, J.-M. Heintz, A. Kawasaki, J.-F. Silvain, Simple Fabrication and Characterization of Discontinuous Carbon Fiber Reinforced Aluminum Matrix Composite for Lightweight Heat Sink Applications. Acta Metallurgica Sinica (English Letters), 27 (2014) 714-722.

[11] Q. Kang, X. He, S. Ren, T. Liu, Q. Liu, M. Wu, X. Qu, Microstructure and thermal properties of copper-diamond composites with tungsten carbide coating on diamond particles. Mater. Charact. , 105 (2015) 18-23.

[12] C. Zhang, X. He, Q. Liu, S. Ren, X. Qu, Fabrication and thermo-physical properties of graphite flake/copper composites. J. Compos. Mater. , 49 (2014) 3323-3330.

[13] W. Li, Y. Liu, G. Wu, Preparation of graphite flakes/Al with preferred orientation and high 
thermal conductivity by squeeze casting. Carbon, 95 (2015) 545-551.

[14] N. Chamroune, D. Mereib, F. Delange, N. Caillault, Y. Lu, J.-L. Grosseau-Poussard, J.-F. Silvain, Effect of flake powder metallurgy on thermal conductivity of graphite flakes reinforced aluminum matrix composites. Journal of Materials Science, 53 (2018) 8180-8192.

[15] M. Murakami, N. Nishiki, K. Nakamura, J. Ehara, H. Okada, T. Kouzaki, K. Watanabe, T. Hoshi, S. Yoshimura, High-quality and highly oriented graphite block from polycondensation polymer films. Carbon, 30 (1992) 255-262.

[16] Q. Fu, J. Yang, Y. Chen, D. Li, D. Xu, Experimental evidence of very long intrinsic phonon mean free path along the c-axis of graphite. Appl. Phys. Lett. , 106 (2015) 031905.

[17] Q. Liu, X.-B. He, S.-B. Ren, C. Zhang, L. Ting-Ting, X.-H. Qu, Thermophysical properties and microstructure of graphite flake/copper composites processed by electroless copper coating. J. Alloys Compd. , 587 (2014) 255-259.

[18] J.M. Molina, E. Louis, Anisotropy in thermal conductivity of graphite flakes-SiCp/matrix composites: Implications in heat sinking design for thermal management applications. Mater. Charact. , 109 (2015) 107-115.

[19] R. Prieto, J.M. Molina, J. Narciso, E. Louis, Thermal conductivity of graphite flakes-SiC particles/metal composites. Composites Part A: Applied Science and Manufacturing, 42 (2011) 1970-1977.

[20] C. Zhou, G. Ji, Z. Chen, M. Wang, A. Addad, D. Schryvers, H. Wang, Fabrication, interface characterization and modeling of oriented graphite flakes/Si/Al composites for thermal management applications. Materials \& Design, 63 (2014) 719-728.

[21] H. Kurita, T. Miyazaki, A. Kawasaki, Y. Lu, J.-F. Silvain, Interfacial microstructure of graphite flake reinforced aluminum matrix composites fabricated via hot pressing. Composites Part A: Applied Science and Manufacturing, 73 (2015) 125-131.

[22] V. Oddone, B. Boerner, S. Reich, Composites of aluminum alloy and magnesium alloy with graphite showing low thermal expansion and high specific thermal conductivity. Sci. Technol. Adv. Mater. , 18 (2017) 180-186.

[23] J.-H. Jang, H.-K. Park, J.-H. Lee, J.-W. Lim, I.-H. Oh, Effect of volume fraction and unidirectional orientation controlled graphite on thermal properties of graphite/copper composites. Composites Part B: Engineering, 183 (2020) 107735.

[24] X. Kai, Z. Li, G. Fan, Q. Guo, Z. Tan, W. Zhang, Y. Su, W. Lu, W.-J. Moon, D. Zhang, Strong and ductile particulate reinforced ultrafine-grained metallic composites fabricated by flake powder metallurgy. Scr. Mater. , 68 (2013) 555-558.

[25] S. Ren, J. Chen, X. He, X. Qu, Effect of matrix-alloying-element chromium on the microstructure and properties of graphite flakes/copper composites fabricated by hot pressing sintering. Carbon, 127 (2018) 412-423.

[26] R. Zhang, X. He, Z. Chen, X. Qu, Influence of Ti content on the microstructure and properties of graphite flake/Cu-Ti composites fabricated by vacuum hot pressing. Vacuum, 141 (2017) 265-271.

[27] A. Veillère, A. Sundaramurthy, J.M. Heintz, J. Douin, M. Lahaye, N. Chandra, S. Enders, J.F. Silvain, Relationship between interphase chemistry and mechanical properties at the scale of micron in $\mathrm{Cu}-\mathrm{Cr} / \mathrm{CF}$ composite. Acta Mater. , 59 (2011) 1445-1455.

[28] C. Azina, J. Roger, A. Joulain, V. Mauchamp, B. Mortaigne, Y. Lu, J.-F. Silvain, Solid-liquid co-existent phase process: Towards fully dense and thermally efficient $\mathrm{Cu} / \mathrm{C}$ composite materials. J. 
Alloys Compd. , 738 (2018) 292-300.

[29] Z. Tan, Z. Li, G. Fan, Q. Guo, X. Kai, G. Ji, L. Zhang, D. Zhang, Enhanced thermal conductivity in diamond/aluminum composites with a tungsten interface nanolayer. Materials \& Design, 47 (2013) 160-166.

[30] A. Boden, B. Boerner, P. Kusch, I. Firkowska, S. Reich, Nanoplatelet size to control the alignment and thermal conductivity in copper-graphite composites. Nano Lett. , 14 (2014) 3640-3644.

[31] A. Morvan, J.-L. Grosseau-Poussard, N. Caillault, F. Delange, S. Roure, P. Lepretre, J.-F. Silvain, Powder processing methodology for fabrication of Copper/Graphite composite materials with enhanced thermal properties. Composites Part A: Applied Science and Manufacturing, 124 (2019) 105474.

[32] N. Iwashita, C.R. Park, H. Fujimoto, M. Shiraishi, M. Inagaki, Specification for a standard procedure of X-ray diffraction measurements on carbon materials. Carbon, 42 (2004) 701-714.

[33] J.Y. Howe, C.J. Rawn, L.E. Jones, H. Ow, Improved crystallographic data for graphite. Powder Diffr. , 18 (2012) 150-154.

[34] P.M. Adams, H.A. Katzman, G.S. Rellick, G.W. Stupian, Characterization of high thermal conductivity carbon fibers and a self-reinforced graphite panel. Carbon, 36 (1998) 233-245.

[35] A.C. Ferrari, J. Robertson, Interpretation of Raman spectra of disordered and amorphous carbon. Phys. Rev. B, 61 (2000) 14095-14107.

[36] F. Tuinstra, J.L. Koenig, Raman Spectrum of Graphite. The Journal of Chemical Physics, 53 (1970) 1126-1130.

[37] A. Eckmann, A. Felten, A. Mishchenko, L. Britnell, R. Krupke, K.S. Novoselov, C. Casiraghi, Probing the nature of defects in graphene by Raman spectroscopy. Nano Lett. , 12 (2012) 3925-3930.

[38] T. Etter, J. Kuebler, T. Frey, P. Schulz, J.F. Löffler, P.J. Uggowitzer, Strength and fracture toughness of interpenetrating graphite/aluminium composites produced by the indirect squeeze casting process. Materials Science and Engineering: A, 386 (2004) 61-67.

[39] T. Etter, P. Schulz, M. Weber, J. Metz, M. Wimmler, J.F. Löffler, P.J. Uggowitzer, Aluminium carbide formation in interpenetrating graphite/aluminium composites. Materials Science and Engineering: A, 448 (2007) 1-6.

[40] Z.Y. Liu, B.L. Xiao, W.G. Wang, Z.Y. Ma, Singly dispersed carbon nanotube/aluminum composites fabricated by powder metallurgy combined with friction stir processing. Carbon, 50 (2012) 1843-1852.

[41] S.R. Bakshi, A. Agarwal, An analysis of the factors affecting strengthening in carbon nanotube reinforced aluminum composites. Carbon, 49 (2011) 533-544.

[42] A. Okura, K. Motoki, Rate of formation of intermetallic compounds in aluminium matrix-carbon fibre composites. Compos. Sci. Technol. , 24 (1985) 243-252.

[43] Z. Tan, G. Ji, A. Addad, Z. Li, J.-F. Silvain, D. Zhang, Tailoring interfacial bonding states of highly thermal performance diamond/Al composites: Spark plasma sintering vs. vacuum hot pressing. Composites Part A: Applied Science and Manufacturing, 91 (2016) 9-19.

[44] C.-W. Nan, R. Birringer, D.R. Clarke, H. Gleiter, Effective thermal conductivity of particulate composites with interfacial thermal resistance. J. Appl. Phys. , 81 (1997) 6692-6699.

[45] P.G. Klemens, D.F. Pedraza, Thermal conductivity of graphite in the basal plane. Carbon, 32 (1994) 735-741.

[46] Y. Sohn, T. Han, J.H. Han, Effects of shape and alignment of reinforcing graphite phases on the thermal conductivity and the coefficient of thermal expansion of graphite/copper composites. 
Carbon, 149 (2019) 152-164.

[47] K. Chu, X.-h. Wang, F. Wang, Y.-b. Li, D.-j. Huang, H. Liu, W.-1. Ma, F.-x. Liu, H. Zhang, Largely enhanced thermal conductivity of graphene/copper composites with highly aligned graphene network. Carbon, 127 (2018) 102-112.

[48] Z.Y. Shen, G. Ji, J.F. Silvain, From 1D to 2D arrangements of graphite flakes in an aluminium matrix composite: Impact on thermal properties. Scr. Mater. , 183 (2020) 86-90.

[49] D.P.H. Hasselman, L.F. Johnson, Effective Thermal Conductivity of Composites with Interfacial Thermal Barrier Resistance. J. Compos. Mater. , 21 (1987) 508-515.

[50] E.T. Swartz, R.O. Pohl, Thermal boundary resistance. Rev. Mod. Phys. , 61 (1989) 605-668.

[51] G. Fan, R. Xu, Z. Tan, D. Zhang, Z. Li, Development of Flake Powder Metallurgy in Fabricating Metal Matrix Composites: A Review. Acta Metallurgica Sinica (English Letters), 27 (2014) 806-815. 